\title{
THE MUTUAL EFFECT OF IRON AND MANGANESE ON MICROSTRUCTURE AND MECHANICAL PROPERTIES OF ALUMINIUM -SILICON ALLOY
}

\author{
Alireza Darvishi $^{{ }^{*}}$, Ali Maleki ${ }^{1}$, Mehdi Mazar Atabaki ${ }^{2}$, Mohammad Zargami $^{3}$ \\ ${ }^{1}$ Graduate School of Science \& Engineering, Yazd University, Iran \\ ${ }^{2}$ Department of Mechanical Engineering, Malaysia Institute of Technology \\ ${ }^{3}$ Supplying Automotives Part Company (SAPCO),Tehran, Iran
}

Received 15.02.2010

Accepted 09.04.2010.

\begin{abstract}
The effect of iron and manganese concentration on the morphology of complex intermetallics and their influence on the mechanical properties and microstructure has been studied in an Al-16.67 wt. \% Si alloy with three content of iron $(0.4,1.2,1.8$ wt.\%), and two different content of manganese, i.e. 0.6 and 0.9 wt.\%. The intermetallic compounds are formed at high iron contents or at high concentrations of manganese with low iron. The microstructural investigation by Clemex software showed that the biggest intermetallic size reached the surface area of $12750 \mu \mathrm{m}^{2}$, when the amount of iron was increased from $1.2 \%$ to $1.8 \%$ wt.\%. It was also showed that the volume fraction of intermetallic compounds increases as the iron and manganese content increases. Formation of complex intermetallic phases with iron adversely affects tensile strength decreasing from $229 \mathrm{MPa}$ with $0.4 \mathrm{wt} . \%$ of iron to $187 \mathrm{MPa}$ when iron content was increased to $1.8 \mathrm{wt} . \%$.

Key words: Hypereutectic Aluminium-silicon alloy; Iron intermetallic; Manganese; Mechanical properties, Intermetalic morphology
\end{abstract}

\section{Introduction}

Iron is a common impurity in aluminium and its alloys that is not readily removed and may cause adverse effects to ductility and castability, particularly in Al-Si based casting alloys. The solid solubility of iron in aluminium is very low with the result that most iron forms intermetallic compounds, the nature of which strongly depends on other present impurities or alloying elements [1,2]. It is expected that with

\footnotetext{
*Corresponding author: Alireza Darvishi alireza_darvishi2001@yahoo.com
} 
increasing the amount of iron from a critical percentage, the $\beta-\mathrm{FeSi}_{5} \mathrm{Al}$ intermetallic inevitably would be formed. This type of intermetallic has the most significant effect on the mechanical properties of Al-Si alloys. It especially decreases ductility because this compound tends to form thin platelets which are very brittle and have substantially low bond strength with the matrix. In addition, platelets and needles of $\beta$ intermetallic have the main negative effects on fluidity, castability, and dendrites channel feeding of the alloy [3] causing unsoundness of castings [4].

A wide range of AlFeSi particle types is reported in the literature. These can generally be divided into three different morphologies: polyhedral crystals, Chinese script, or thin platelets. These phases are dominant in slowly cooled castings, whereas the metastable phases $\mathrm{Al}_{6} \mathrm{Fe}$ (orthorhombic) and $\alpha /-\mathrm{Al}_{20} \mathrm{Fe}_{5} \mathrm{Si}_{2}$ (cubic) only occur in rapidly quenched material. Since many commercial aluminium alloys contain manganese, it is to be expected that the cubic $\alpha-\mathrm{AlFeSi}$ phase will be found in these alloys rather than the hexagonal $\alpha$-AlFeSi phase [5-9].
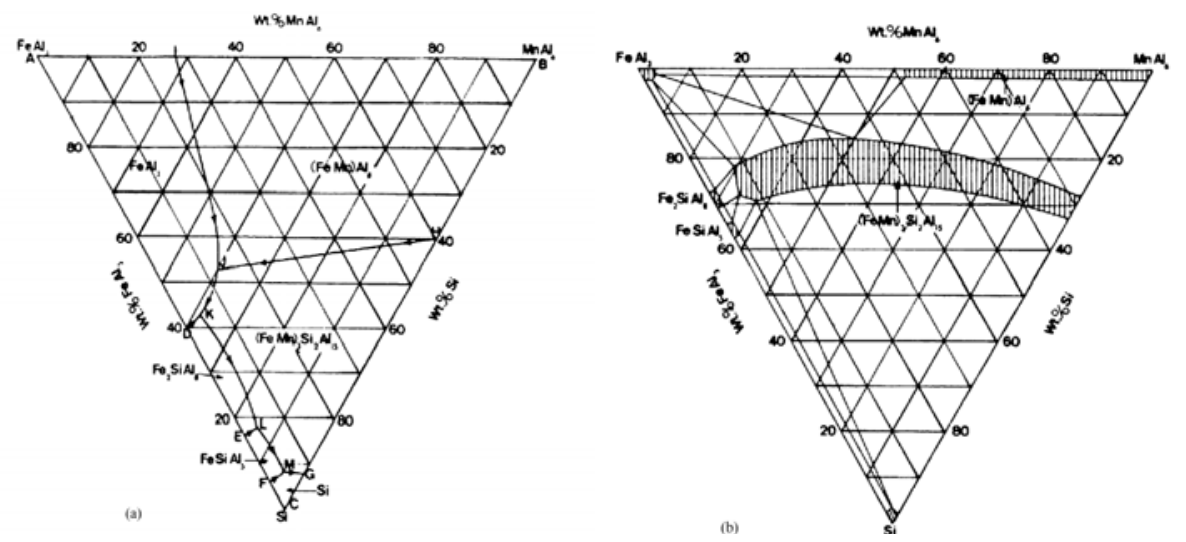

Fig. 1. Projection of the aluminium corner of the aluminium-iron-manganese-silicon diagram: (a) liquidus; (b) phase distribution in the solid (after Ref. [5]).

Manganese is also able to change the morphology of the iron-rich phases from platelets to a more cubic form or to globules. These morphologies improve tensile strength, elongation, and ductility $[10,11]$. If the iron content exceeds $0.45 \mathrm{wt} \%$, it is reported that the manganese content should not be less than half of the iron (Fig. 1) [3]. A manganese concentration over $0.6 \mathrm{wt} . \%$ causes segregation whether the iron content is 0.8 or $2.3 \mathrm{wt} . \%$. Thus, manganese is more powerful than iron in causing gravity segregation. The liquidus and the solid-state distributions of phases in the quaternary aluminium-iron-manganese-silicon system are shown in Fig. 1. None of the present phases that appear is truly quaternary: the $(\mathrm{FeMn})_{3} \mathrm{Si}_{2} \mathrm{Al}_{15}$ is the ternary $\mathrm{Mn}_{3} \mathrm{Si}_{2} \mathrm{Al}_{15}$ in which iron replaces up to $90 \%$ of the manganese so that its field extends far toward the $\mathrm{Fe}-\mathrm{Si}$ side $[13,14]$. In many alloys, $(\mathrm{FeMn}) \mathrm{Al}_{6}$ then reacts peritectically with the liquid to form $(\mathrm{FeMn})_{3} \mathrm{Si}_{2} \mathrm{Al}_{15}$.

In the present research the effect of iron and manganese on intermetallic morphology and mechanical properties of as-cast $\mathrm{Al}-16.67 \% \mathrm{Si}$ alloy in metal mould is presented. 


\section{Experimental procedure}

\section{Microstructural study and phase analysis}

In the present research a hypereutectic alloy, $\mathrm{Al}-16.67 \% \mathrm{Si}$, was selected for casting in metal mould. The chemical composition of the alloy prepared for the present investigation is shown in Table 1. Since the weight loss was negligible during casting, the nominal compositions of $\mathrm{Al}-16.67 \mathrm{wt} . \% \mathrm{Si}$ could be regarded as the true composition in the current study. Further elemental analysis by energy dispersive X-ray spectroscopy (EDX) indicated that the average composition was well consistent with the nominal composition (see Table 1).

Table 1. Chemical composition of the hypereutectic Al-Si alloy (wt. \%).

\begin{tabular}{|c|c|c|c|}
\hline & Aluminium (wt \%) & Silicon (wt \%) & Iron (wt \%) \\
\hline $\begin{array}{c}\text { Numerical } \\
\text { composition }\end{array}$ & 82.93 & 16.67 & 0.4 \\
\hline True composition & $82.93 \pm 0.2$ & $16.67 \pm 0.2$ & $0.4 \pm 0.2$ \\
\hline
\end{tabular}

In order to prepare samples, a mass of 450 grams of liquid metal was melted in a graphite crucible in an induction furnace ( $F-47$ model), poured into a copper mold with a hollow cavity of the bloom shape, and then allowed to solidify. The cooling rate of the mold was $10^{\circ} \mathrm{C} / \mathrm{s}$. These samples were subsequently metallographically examined in order to determine the effect of variations in chemistry on the intermetallic morphology. Iron and manganese were added to this alloy by means of commercial master alloys of composition: Al-20 Fe (wt. \%) and Al-23 Mn (wt. \%) The value of iron and manganese was calculated by following formulas [19]:

Added iron $=$ liquid weight $\times(0.4$ - final volume of iron $) \times 0.05+4 / 300$

Added manganese $=$ liquid weight $\times$ final volume of manganese $\times 0.05+4 / 300$

Samples were melted in a graphite crucible in an induction furnace, and the melt was maintained at $900^{\circ} \mathrm{C}$ for $1.5-2.0 \mathrm{~h}$ in order to complete dissolution of the intermetallics and homogenize silicon. After dissolution of the compounds, the alloys were maintained at $730^{\circ} \mathrm{C}$ for $20 \mathrm{~min}$ and then samples were poured into the copper mold. In another experiment the casting cycle was maintained at $850^{\circ} \mathrm{C}$ for $1.5-2.15 \mathrm{~h}$. In this step, after homogenizing the silicone, iron was added to the alloy. Molten metal was held in the furnace for 5 min to completely dissolve iron in the matrix. Molten metal was brought out from the furnace and manganese was added to the molten metal. Likewise, dissolving manganese was carried out when the molten metal was maintained outside the furnace for $10 \mathrm{~min}$. Afterward the molten metal was moved into the furnace and maintained at $730^{\circ} \mathrm{C}$ for $15 \mathrm{~min}$, and in this period degassing was carried out with Hegzacloroethan. Both refiner and modifier were added to the melt in the form of short, thin rods. After mechanical stirring, the melt was allowed to dwell for 4 min, followed by a degassing stage lasting approximately $10 \mathrm{~min}$. Then the melt was poured on the slight steep (with an angle of $48^{\circ}$ ) surface made of copper. A schematic description of the manufacturing process is depicted in Fig. 2. 


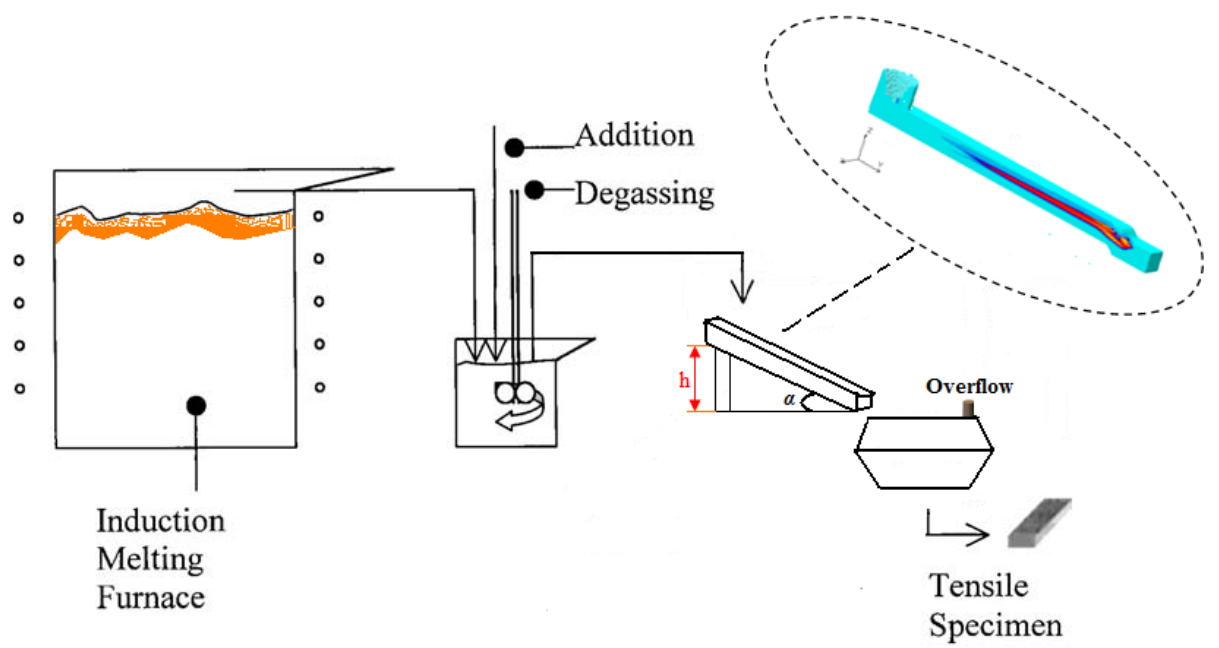

Fig 2. Schematic description of the manufacturing process.

In order to modify primary silicon particles, $0.15 \mathrm{wt} . \%$ of phosphorus was added to charge before casting. The samples were divided into three groups:

1- Al-Si-0.4Fe (starting alloy)

2- Al- Si- $1.2 \mathrm{Fe}-0.6 \mathrm{Mn}$

3- Al- Si- $1.8 \mathrm{Fe}-0.9 \mathrm{Mn}$

All samples were prepared for metallographic examination and image analysis. Morphology and identification of intermetallic compound were investigated and measured using image analysis, such as the particle area $\left(\mu \mathrm{m}^{2}\right)$, average size $(\mu \mathrm{m})$, number of particles per unit volume $\left(\mathrm{mm}^{-3}\right)$, and volume percentage $(\%)$. The data was automatically processed by image analysis software (Clemex) using statistical programs and the average values are reported in this paper.

Meanwhile, samples were mounted in the bakelite and mounted sections were identified by the vibrating pen. All samples were grinded by a series of SiC papers, i.e. 240, 320, 400 and 600 grades. Mounts, however, were carefully bevelled. Polishing performed with $6 \mu \mathrm{m}$ diamond paste was followed by polishing with colloidal silica slurry. A mixture of water solution of $\mathrm{HF}(0.5 \%)$ and $\mathrm{NaOH}(15 \%)$ was used as etchant of polished samples.

\section{Mechanical properties of the hypereutectic alloy}

In order to reveal positive or negative effect of intermetallics, two types of mechanical tests have been performed in this study. After casting samples were suitably prepared by a cutter machine and kept at room temperature in a bottle filled with acetone $\left(\mathrm{CH}_{3} \mathrm{COCH}_{3}\right)$ to prevent oxidation. According to ASTM-E8 standard, tensile tests were carried out on round specimens having diameters of $8.75 \mathrm{~mm}$ with the total length of $85 \mathrm{~mm}$, whereas the gauge length was $20 \mathrm{~mm}$. The samples were tested using a screw-driven univesal machine (Gotech). Hardness tests were carried out by KarlClob machine. The applied load according to ASTM E-10 standard was usually 1.500 or $500 \mathrm{kgf}$, so that the diameter of the indentation was in the range from 2.5 to $6.0 \mathrm{~mm}$. 
The load was applied steadily without a jerk. The full test load was applied for 10 to 15 seconds. Two diameters of impression at right angles were measured, and the average diameter was used as a basis for calculating the Brinell hardness number (BHN), which was done using the conversion table given in the standard.

\section{Results and discussion}

\section{Microstructural study and phase analysis} $\underline{\mathrm{Al}-\mathrm{Si}}$

As can be seen from Fig. 3 a mixture of eutectic phases was formed in the aluminium matrix. Because the samples were exposed to high-undercooling, the fine and homogenous primary silicon islands appeared in the matrix. When the liquidus temperature was reached some of the liquid solidifies and crystallizes into the solid phase $\beta$. Additional heat removal was required to form a higher amount of $\beta$-phase between the liquidus and solidus temperatures (Fig.4). From the thermodynamic point of view nucleation of primary $\beta$-phase in an inclusion-free aluminium matrix requires supersaturation. Therefore, spontaneous reaction of the secondary phase is dictated by thermodynamic of particles, which have a very high activity.
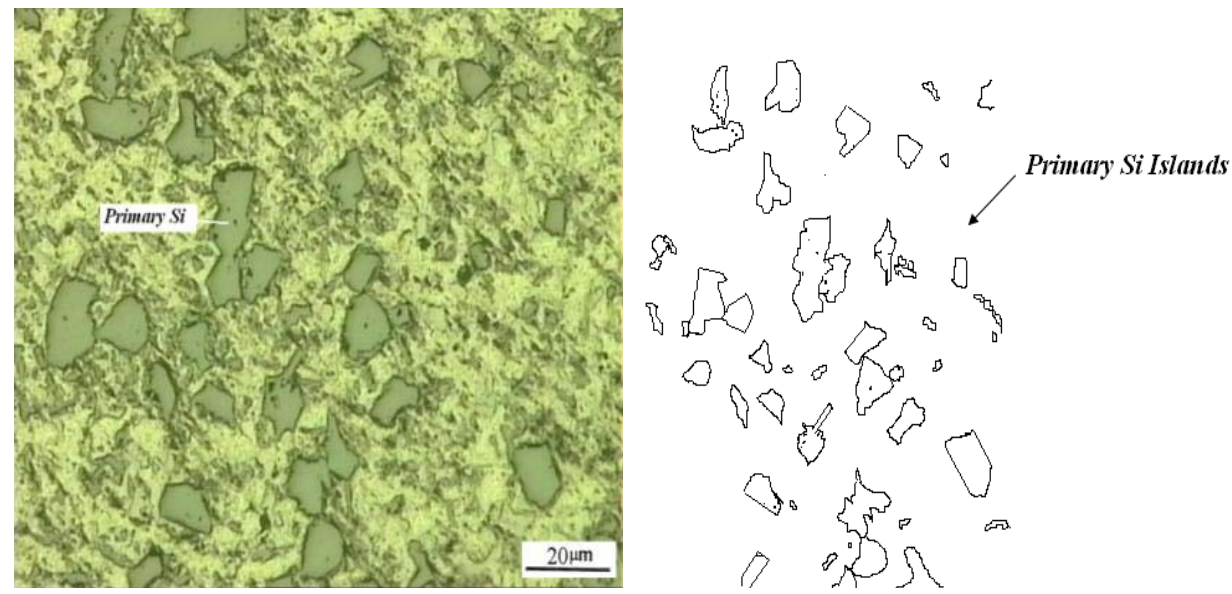

Fig 3. The microstructure of the starting Al-16.67 wt.\% Si alloy without additional alloying elements.

The solidification of the $\mathrm{Al}-16 \% \mathrm{Si}$ alloy (without alloying elements) starts with the precipitation of $\beta$-Al dendrites followed by a residual liquid which, on reaching a critical concentration of silicon, develops a lamellar eutectic alloy (Figs.3 and 4). When the starting composition is hypereutectic, as in the present study (Alloys-1, 2 and 3), it is possible for solidification to begin with the nucleation of silicon on the available places in the liquid. As a result, the composition of the remaining liquid first moves away from the coupled zone where the eutectic reaction occurs. The growth of the cuboids generates a depletion of silicon in the solid-liquid interface. A halo of high aluminium content is developed and, depending on both the number of nuclei formed and the growth rate of the silicon phase, the volume fraction of aluminium-enriched 
liquid varies accordingly. If the thermodynamic and kinetic conditions allow $\beta$ - $\mathrm{Al}$ to precipitate from these haloes onto the cuboids, the composition of the remaining liquid changes again, and becoming gradually enriched in silicon moves into the coupled zone [15]. The primary silicon crystals are also distributed relatively homogeneously.
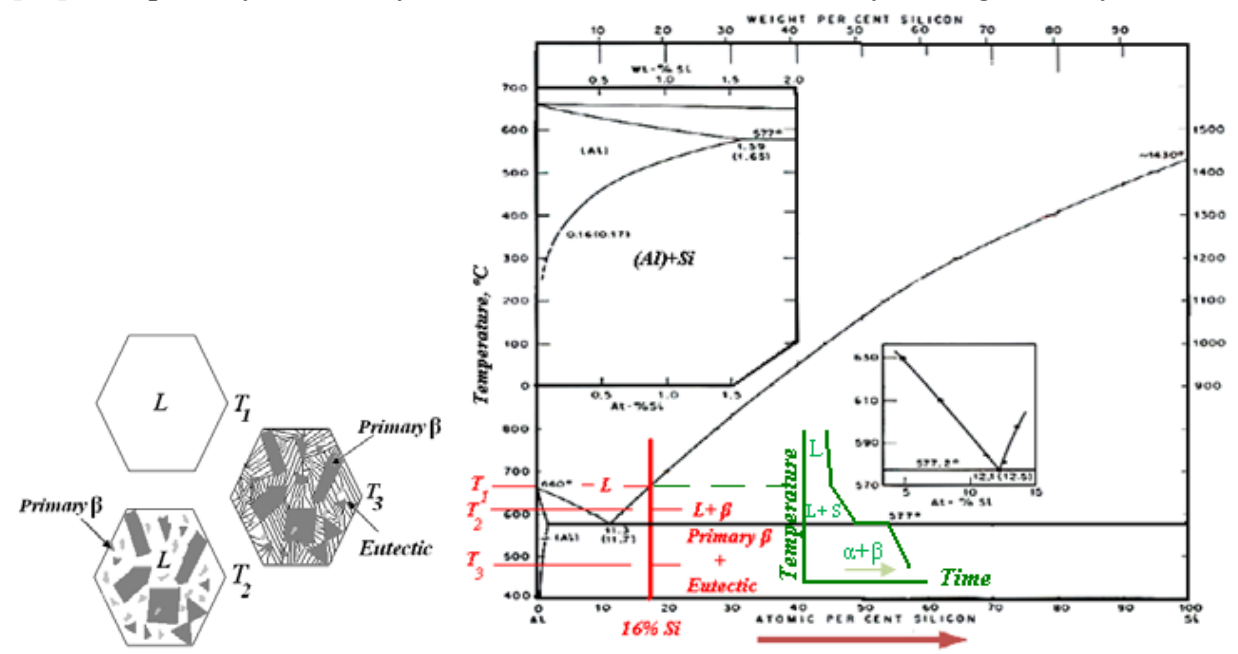

Fig 4. Phase diagram of Al-16\%Si binary alloy.

In the Al-Si alloy the initial bump can be attributed to nucleation and growth of a small quantity of secondary aluminium on primary silicon which is then followed by the usual flake eutectic growth. The flake eutectic structure also uniformly grows between the increasingly large proportions of primary aluminium.

\section{$\underline{\text { Al-Si-Fe-Mn }}$}

When iron and manganese were added to the alloy the microstructural appearance and the entire mechanical properties of the alloy has been changed. The addition of iron to the Al-Si alloy causes a slight increase in the lattice constant [16], enabling more intermetallics to be formed. Although iron is highly soluble in the liquid aluminium and its alloys, it has a very low solubility in the solid, and tends to combine with other elements to form intermetallic phase particles of various types. According to the Taylor's law [18] $\left[\mathrm{Fe}_{\text {critical }}=(0.075 \times \% \mathrm{Si})-0.05\right]$ it was normal to expect to have enough detrimental intermetallics, e.g. at above $1.2 \%$ iron. In the absences of silicon the dominant phases are $\mathrm{Al}_{3} \mathrm{Fe}$ and $\mathrm{Al}_{6} \mathrm{Fe}$, but when silicon is present, the dominant phases are $\mathrm{Al}_{8} \mathrm{Fe}_{2} \mathrm{Si}$ (known $\alpha$-phase) and $\mathrm{Al}_{5} \mathrm{FeSi}$ (known as $\beta$-phase) (see Fig. 5).

The Fe-Si phase diagram shows that the fcc solid solution based on iron is restricted by a $\gamma$ loop. The bcc solid solution $(\alpha-\mathrm{Fe})$ exists in disordered A2 form and the ordered $\mathrm{B} 2$ structure. The $\mathrm{A} 2 \rightarrow \mathrm{B} 2$ transition is of the second degree order occurring down to $700^{\circ} \mathrm{C}$; and below this temperature it becomes of the first degree order with an intervening $\left(\mathrm{B}_{3}+\mathrm{DO}_{3}\right)$ two-phase field. The intermediate phases in the system are $\mathrm{Fe}_{2} \mathrm{Si}$, $\mathrm{Fe}_{5} \mathrm{Si}_{3}, \mathrm{FeSi}$, and $\mathrm{FeSi}_{2}$. There are two polymorphs of $\mathrm{FeSi}_{2}$ : the low-temperature $\alpha \mathrm{FeSi}_{2}$ occurs at the stoichiometric composition; whereas the high-temperature $\beta-\mathrm{FeSi}_{2}$ is $\mathrm{Fe}$ deficient (Fig. 5). The iron-containing intermetallic phases listed above may be found within the microstructures of Al-16.67 \% Si alloy. Inspecting Fig. 6 it may be revealed 
that both phases have a script-like morphology. Intermetallic particles formed prior to the solidification of the aluminium dendritic grain network (i.e. growing freely within the liquid) or those formed at the same time as the dendritic network (but within the remaining liquid) tend to grow much larger than those formed later, during or after the period of Al-Si eutectic solidification, due to a less liquid space available for growth to occur during these later stages. In general, the larger the particle, its effect is more likely detrimental on mechanical properties. Increasing the concentration of iron (and also manganese) tends to result in earlier formation of intermetallic phase particles and hence more unconstrained growth is able to occur (see Fig. 7). A slower cooling rate also increases the risk of formation large particles because the time available for growth is increased.

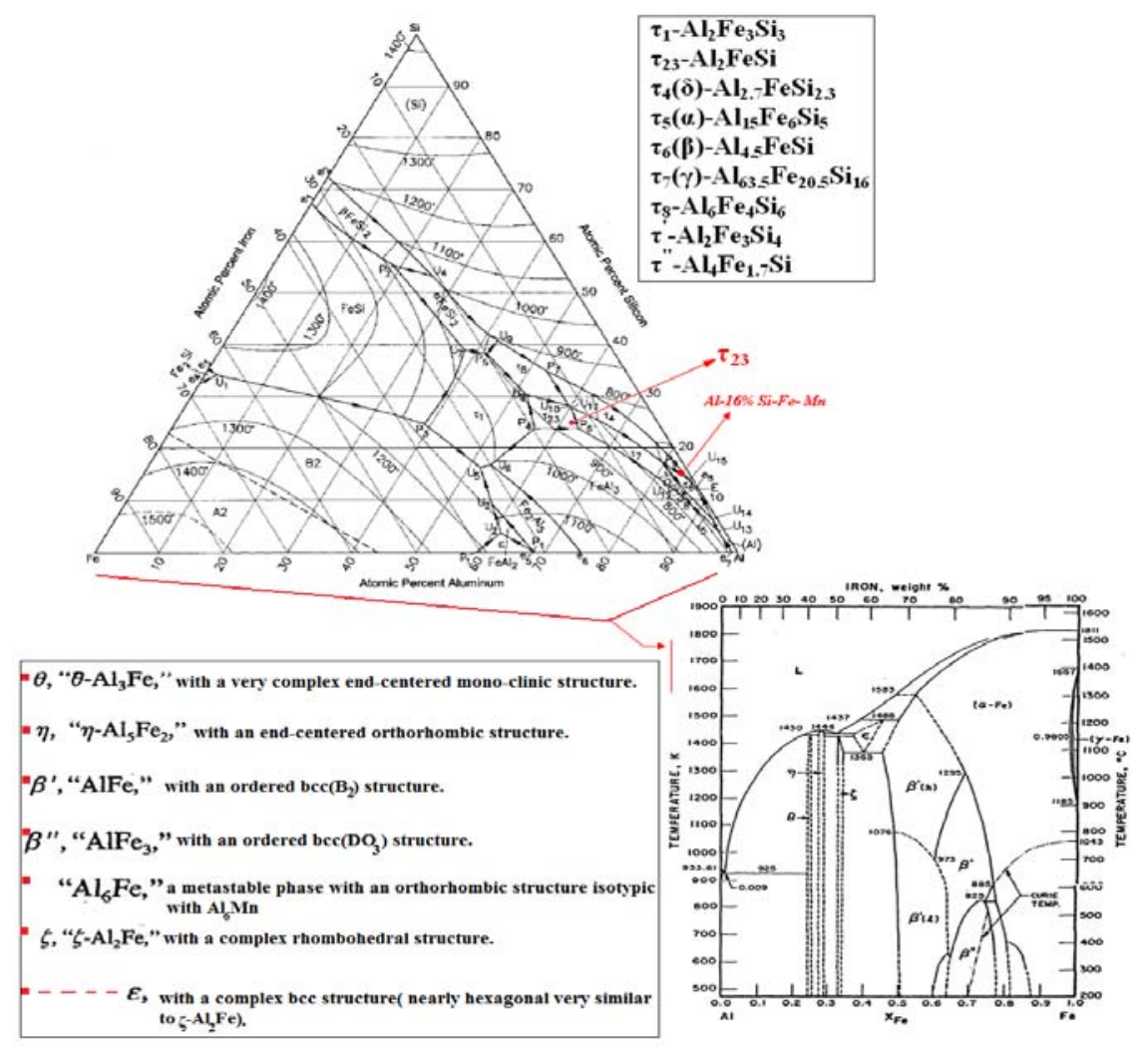

Fig 5. Al-Fe-Si liquidus projection in atomic percent.

Iron-bearing intermetallics (especially $\alpha-\mathrm{Al}_{15}(\mathrm{Fe}, \mathrm{Mn})_{3} \mathrm{Si}_{2}$-script) can grow up to two or more millimeters in slowly-cooled Al-Si alloy castings with high iron and/or manganese levels. However, under casting conditions applied in this work, these intermetallics grow more typically in the size ranging from 80 to $600 \mu \mathrm{m}$. Fig. 6 shows microstructure of $\mathrm{Al}-\mathrm{Si}-1.2 \mathrm{Fe}-0.6 \mathrm{Mn}$ alloy. As can be seen, the $\alpha$-phase is formed as a result of interaction between iron and manganese. In addition, the presence of iron and manganese cause semi-diffusion interface between guest phases and the matrix. It was 
also seen that when the iron content increases from 1.2 to $1.8 \mathrm{wt} . \%$ star-like compounds form at low levels of manganese, and if manganese content is high enough all intermetallics are star-like.

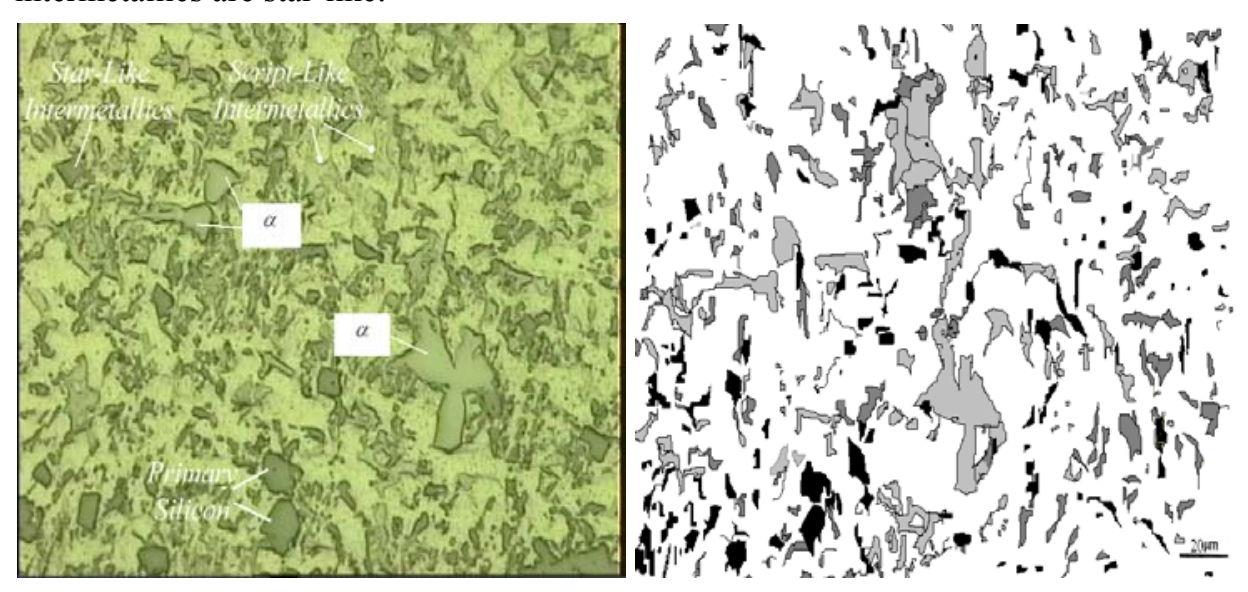

Fig 6. Metallogrphic microstructure of Al-Si-1.2Fe-0.6Mn.

Any increase in the volume percentage of intermetallics in all alloys is related to the size and the volume fraction of particles formed in a unit volume (see Fig. 6). It may be assumed that when more iron was added to the alloy, more driving force is produced; resulting in a decrease of the total surface energy of solid silicon, which can be accomplished by lowering the surface area per unit volume of present phases. Consequently, this leads to a theoretically high tendency of this type of hypereutectic alloy to develop a fine microstructure and epitaxial growth instead of the more frequent random lamellar and coherent form. It is found that manganese accelerates the nucleation of iron-based intermetallic crystals in high undercooling process. In this alloy, $(\mathrm{FeMn}) \mathrm{Al}_{6}$ reacts peritectically with the liquid and then $(\mathrm{FeMn})_{3} \mathrm{Si}_{2} \mathrm{Al}_{15}$ is formed. There are many other reactions in the system, for instance, liquid reacts with $\mathrm{FeSiAl}_{15}$ yielding aluminium plus silicon plus $(\mathrm{FeMn})_{3} \mathrm{Si}_{2} \mathrm{Al}_{15}$. By this reaction the $\mathrm{FeSiA}_{15}$ platelets that badly embrittle high silicon alloys are transformed into the $(\mathrm{FeMn})_{3} \mathrm{Si}_{2} \mathrm{Al}_{15}$ phase that does not appreciably affect the mechanical properties of alloys (see Figs 5 and 6). $(\mathrm{FeMn})_{3} \mathrm{Si}_{2} \mathrm{Al}_{15}$ crystals are primary and as they tend to be limited by the (111) faces, they appear in well-formed hexagons. As iron content increases in each alloy, more intermetallic compounds are formed and consequently the volume fraction of these compounds increases. The iron effect is more significant in alloys which have higher levels of manganese. Any increase in the volume fraction of intermetallics in all alloys is related to the size and the number of particles formed in a unit volume (Fig. 8 and Table 2). In contrast, the results show a significant enlargement in grain size measured by area when only manganese is added at $0.8 \mathrm{wt. \%}$ (see Fig. 7). When the iron and manganese are simultaneously added to the melt, it may be concluded that iron is innocuous with regard to significantly altering both the volume fraction and the particle size of the primary silicon cuboids. 


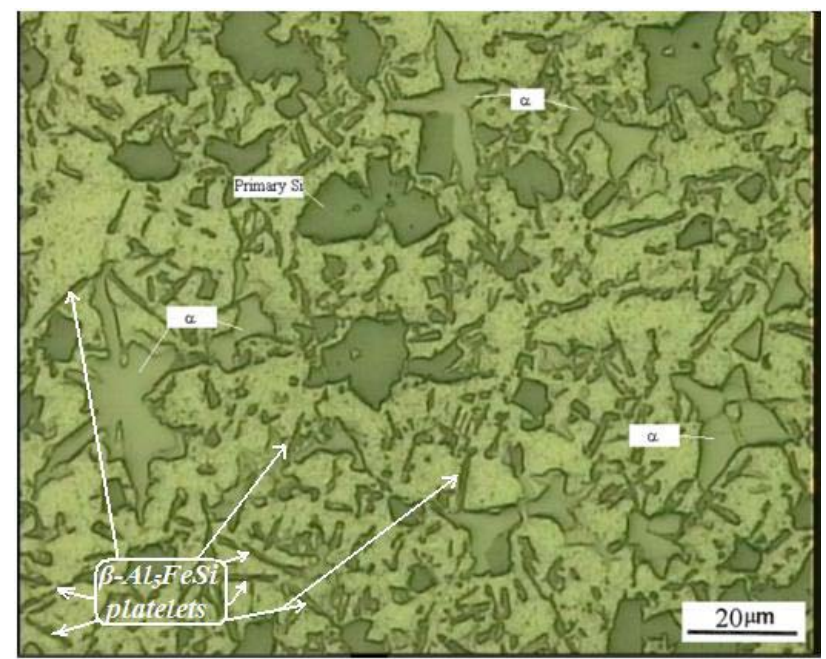

Fig 7. Metallogrphic microstructure of Al-Si-1.8Fe-0.8Mn.

The results of the average size and the volume fraction of particles measured by image analysis are given in Fig. 8. This figure indicates that the size of intermetallics as well as the number of particles increase with manganese, and/or iron content in the alloys. However, the contribution of the number of particles in increasing the volume fraction of intermetallics is more significant than that of particle size.

Table 2. The average size and the volume fraction of intermetallics per unit volume.

\begin{tabular}{|c|c|c|}
\hline Alloy & Size $(\mu \mathrm{m})$ & Volume fraction $(\%)$ \\
\hline 1 & ----- & ---- \\
\hline 2 & $6.4 \pm 3.2$ & 5.3 \\
\hline 3 & $8.6 \pm 6.7$ & 9.6 \\
\hline
\end{tabular}

The results of image analysis of the samples are shown in Figs 8 and 9. In Fig. 9, the volume fraction of all intermetallics present in Alloys 2 and 3 is plotted as a function of iron concentration at various levels of manganese content. As iron content increases in each alloy, more intermetallic compounds are formed and consequently the volume fraction of these compounds increases. The iron effect is more significant in producing more intermetallics, which have higher levels of manganese. From Fig 9 it is clearly seen that the number of phases versus area is increased by adding more iron and manganese. For example, in Alloy 2 in the area of $750 \mu \mathrm{m}^{2}$ four phases are formed, while in Alloy 3 in the largest area, $1050 \mu \mathrm{m}^{2}$, just one phase exists. Also, this figure shows that in Alloy 3 the biggest intermetallic particle reached the surface area of 12750 $\mu \mathrm{m}^{2}$ when the amount of iron was increased from 1.2 to $1.8 \mathrm{wt} \%$. Presence of manganese in the alloys causes considerable decrease in the length of fine $\beta-\mathrm{Al}_{15} \mathrm{FeSi}$ phase. Moreover, manganese forms a semi-diffusion interface between guest phase and the matrix. 


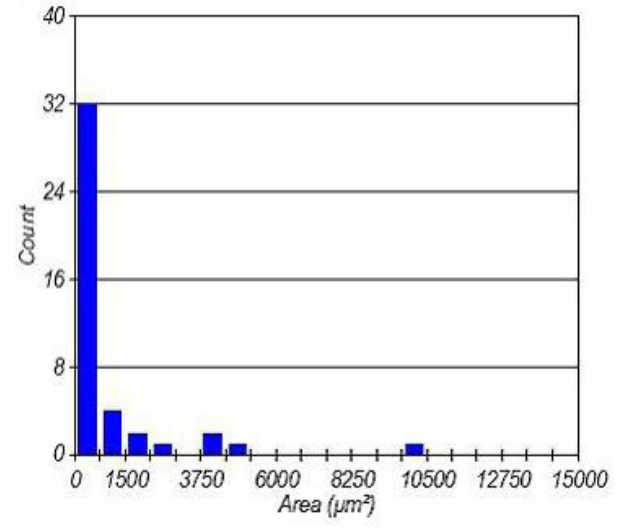

(a) Alloy 2 - Al-Si-1.2Fe-0.6Mn

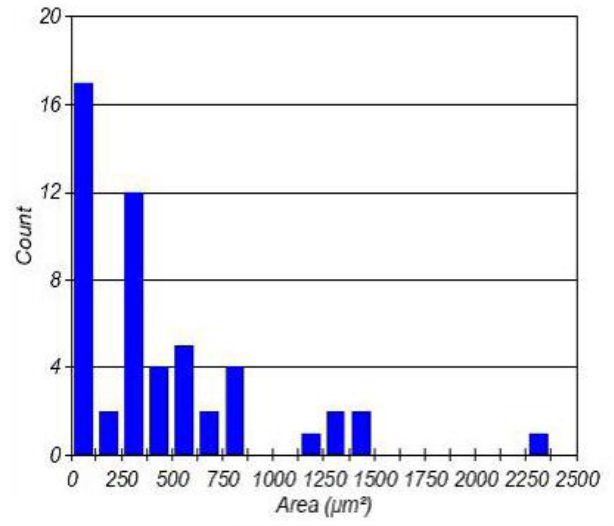

(b) Alloy $3-$ Al-Si-1.8Fe- $0.9 \mathrm{Mn}$

Fig 8. The number of phases in a microstructural area $\left(\mu m^{2}\right)$.

It is revealed that discontinuity of surface areas between primary silicon crystals and the matrix appear as dark boundaries (Fig. 7). Nonetheless, semi-diffusion interface between refined phases and matrix appeared lighter in the whole matrix.

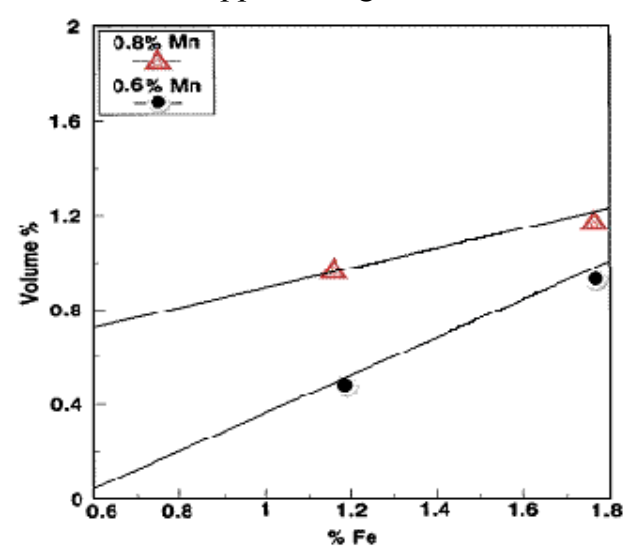

Fig. 9. The volume fraction of intermetallics as a function of iron concentration at two levels of manganese.

The ternary phase diagram of Al-Si-Mn is shown in Fig. 10 with the intention of revealing whether it is possible for other types of intermetallics to be formed. As it can be seen from the left bottom part of the diagram referring to manganese alloys used in this study, it may be expected to identify very rare $\tau_{9}$ (shown in the corner of the diagram) intermetallics which are quite difficult to be metallographically identified in the microstructure. This shows that the result in Fig. 9 is in accordance with the aspects of the ternary phase.

It is interesting to note that by increasing the manganese content, the ternary aluminium-silicon-manganese eutectic is avoided and thus, quite unexpectedly, a 
relatively narrow solidification range is provided. These changes enable substantially improved castability over ternary hypereutectic aluminium silicon alloys. In this alloy the iron and manganese tend to harden the alloy and decrease its thermal expansion. Silicon precipitates during cooling as relatively large-scale crystals. However, at the surface of the casting the silicon particles appear as fine and small. Cross sections of the cast alloys revealed the $\alpha+\mathrm{Al}_{5} \mathrm{SiFe}+\mathrm{Si}$ eutectic system and a laminar phase, in an amount which increases with increase in iron content. Increasing amount of manganese, iron becomes partially bound in ternary intermetallic compounds.

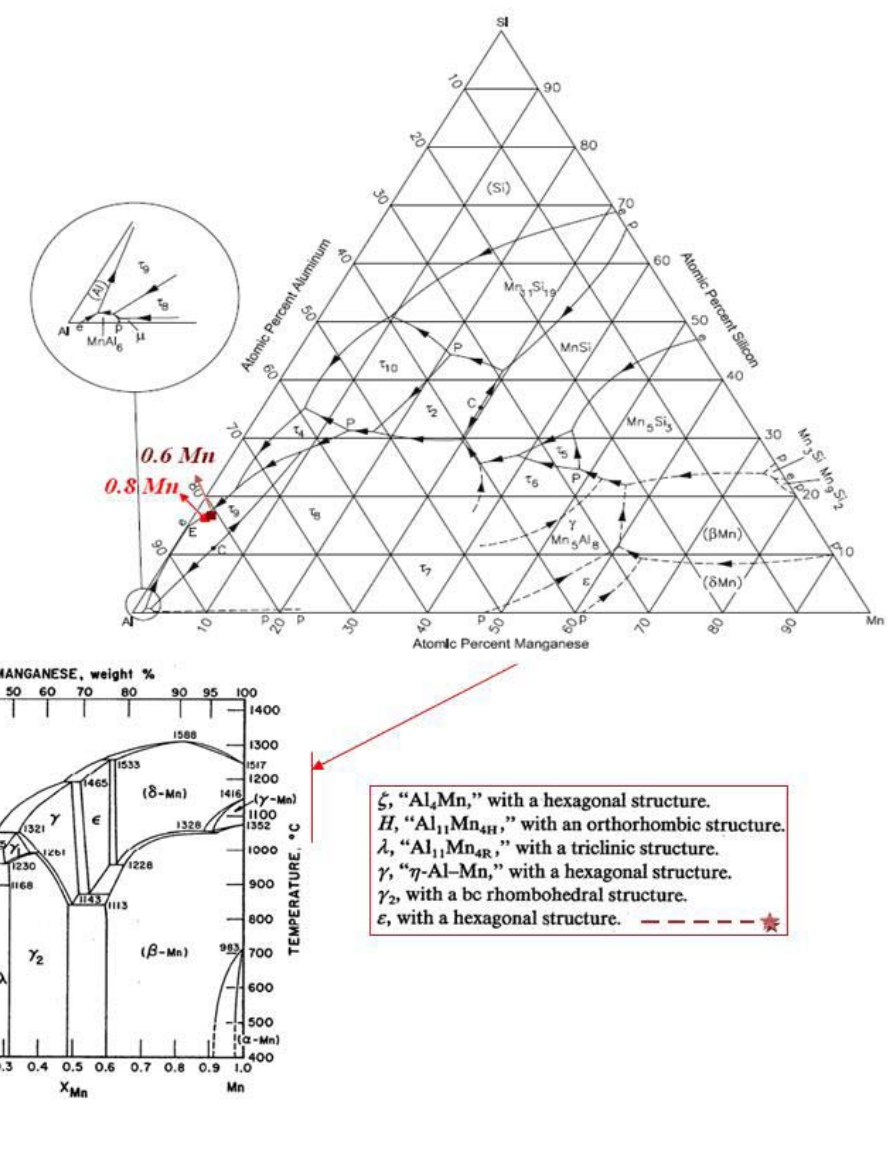

Fig 10. Al-Mn-Si liquiudus projection of hypereutectic Al-Si-Mn [15].

It should be pointed out that increase in manganese affects the solubility of iron in aluminium at high temperature. It was observed by Zhmudskii et al. [17] that a change in the manganese concentration causes the change in the lattice constant of $\alpha$ solid solution. It means that manganese dissolves jointly in aluminium and decreases the lattice constant of the solid which led iron to react with silicon forming new intermetallics. These intermetallics were mostly formed within aluminium dendrites. 
The intermetallics consume some of the silicon present in the alloy and shift the local chemical composition of the melt to the aluminium side of the phase diagram, with the result that primary aluminium dendrites form around the intermetallics [16]. Under the same circumstances, the phase $\mathrm{Al}_{6}(\mathrm{Mn}, \mathrm{Fe})$ has a considerable equilibrium solubility for iron permitting substitution of more than a half of manganese atoms with iron. In fact, the phase $\mathrm{Al}_{6} \mathrm{Fe}$ is expected to be formed in ternary $\mathrm{Al}-\mathrm{Si}-\mathrm{Fe}$ alloys solidified at highest cooling rates. Clearly, the small difference between the stable and the metastable eutectic temperatures is one of the reasons for the ease at which $\mathrm{Al}_{3} \mathrm{Fe}$ is replaced by $\mathrm{Al}_{6} \mathrm{Fe}$ in eutectics with aluminium by slight undercooling prior to solidification or growth.

\section{The effect of iron and manganese on mechanical properties}

The effect of iron and manganese on microhardness

The effect of iron on the mechanical properties of aluminium alloys showed that as iron levels increase from 1.2 to $1.8 \mathrm{wt} . \%$, the hardness of Al-Si based alloys increases (Fig. 11). The effect of iron on hardness can be described by the size and volume fraction of iron-containing intermetallics (particularly $\beta$-phase) which are increased with iron content. However, as iron level increases, porosity increases, and these defects also have a significant impact on hardness.

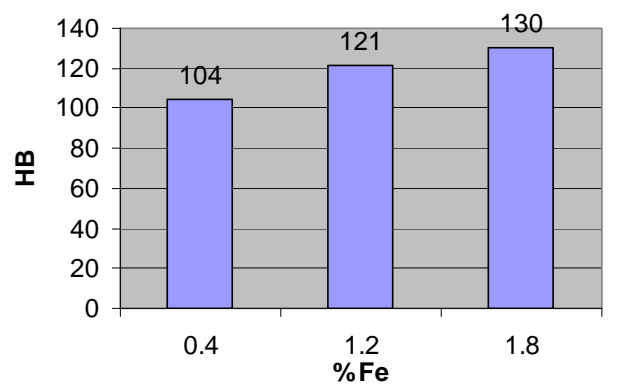

Fig 11. The effect of iron addition on the hardness of hypereutectic Al-Si alloys.

It is found that increase in iron content leads to an increase in alloy hardness. According to Fig. 11, the highest hardness, $130 \mathrm{HB}$, is related to the alloy with $1.8 \mathrm{wt} . \%$ of iron.

\section{The effect of iron and manganese on tensile strength}

The results of tensile strength (UTS) of as-cast Al-Si alloys with different content of iron fall along dashed-line shown in Fig. 12. The results of UTS show that when iron increases, the UTS steadily decreases and from $229 \mathrm{MPa}$ with $0.4 \mathrm{wt} \%$ of iron drops to $187 \mathrm{MPa}$ when iron content reaches $1.8 \mathrm{wt} . \%$. The various parameters such as intermetallics present in the matrix, solidification cooling rate (secondary dendrite arm spacing - SDAS) and higher iron content affects the strength of Al-Si alloys. As an alloy contains higher iron content, i.e. higher amount of intermetallics is present in the matrix, the UTS moves to lower levels. 


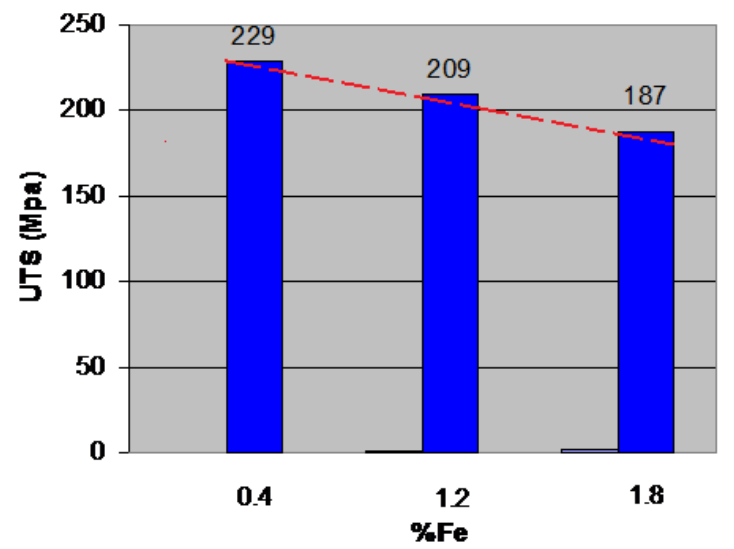

Fig 12. The effect of various iron content on the tensile strength of Al-Si alloys.

A copper mold increases the cooling rate, but decreasing the SDAS in the same time. The reason that iron-containing intermetallic particles are detrimental to mechanical properties is that they are much more easily fractured under the tensile load than the aluminium matrix or the small silicon particles (modified by manganese). Although the amount of manganese was also increased it seems that the role of iron in decreasing strength is prevailing. Moreover, it may be supposed that the addition of manganese in some extent suppresses the negative effect of iron on the strength of Al-Si based alloys.

\section{Conclusions}

The following conclusions can be drawn from the results of the present investigation:

The volume fraction of intermetallic compounds increases as the iron or manganese content increases in any of Al-Si based alloys. This increase has been found to be a result of size and the number of $\beta$-phase and star-like intermetallic compounds.

Iron and manganese have different effects on the microstructure and mechanical properties of hypereutectic Al-Si alloy. In addition, manganese and iron form ternary compounds with aluminium and silicon.

The hypereutectic Al-Si with higher iron and manganese has higher hardness and lower tensile strength. However, manganese reduces the intensity of negative effect of iron on tensile strength.

\section{References}

[1] Pat L. Mangonon, P. E. Fasm, The principles of Materials Selection for Engineering Design, Prentice-Hall International, Inc, 1999, pg 560-563. 
[2] N.A. Belov, A.A. Aksenov, Iron in Aluminium Alloys: Impurity and Alloying Element, Taylor \& Francis Inc, New York, 2002.

[3] A. Couture, AFS Inter. Cast Metals J. 6 (4) (1981) 9-17.

[4] J.E. Eklund, On the Effects of Impurities on the Solidification and Mechanical Behavior of Primary and Secondary Commercial Purity Aluminium and Aluminium Alloys, Ph.D. thesis, Helsinki University of Technology, 1991.

[5] L.F. Mondolfo, Aluminium Alloys: Structure and Properties, Butterworths, 1976.

[6] G. Phragmen, J. Inst. Metals 77 (1950) 489-553.

[7] J.N. Pratt, G.V. Raynor, J. Inst. Metals. 79 (1951) 211-232.

[8] P. Liu, T. Thorvaldsson, G.L. Dunlop, J. Mat. Sci. Tech. 2 (1986) 1009-1018.

[9] V. Stefaniay, A. Griger, T. Turmezey, J. Mater. Sci. 22 (1987) 539-546.

[10] S.G. Shabestari, M. Mahmudi, M. Emami, J. Campbell, Inter. J. Cast Metals Res. 15 (2002) 17-24.

[11] J.L. Jorstad, Die Casting Eng., November/December 1986.

[12] W.H. Glaisher, Metallurgia 43 (1951) 127-131.

[13] L.F. Mondolfo, Manganese in Aluminium Alloys, The Manganese Center, Paris, 1978.

[14] X. Cao, J. Campbell, AFS Trans. 61 (2000) 391-399.

[15] Gruzleski JE. Coupled zone-microstructure relationships in cast eutectics. Microstructure development during metalcasting. Des Plaines, IL: American Foundrymen's Society Inc.; 2000. p. 208-11.

[16] V. Raghavan, Aluminium-Manganese-Silicon, JPEDAV (2007) 28:192-196.

[17] A. Z. Zhmudskii, et. al., Effect of Nickel, Iron, and Manganese on the Solubility of Copper in the Allot Al-10\% Si, UDS 539.21:536.42.

[18] John A. Taylor, The Effect of Iron in Al-Si Casting Alloys, Cooperative Research Centre for Cast Metals Manufacturing (CAST), The University of Queensland, 2003

[19] Iwahori H, Takamiya H, Yonekura K, Yamamoto Y, Nakamura M, "Influence of iron and manganese on feedability of AC2B alloy", Imono (in Japanese), 60(9), pp. 590-595, 1988. 